\title{
On Some Universal and Specific Semantic and Cognitive Aspects of the Emotive Joyin English
}

\author{
Shushanik Melik-Adamyan \\ Russian-Armenian (Slavonic) University
}

\begin{abstract}
The most widespread distinction made between emotions seems to be their being positive or negative; however, there is much more to their linguistic study. Joy is seen as one of the primary emotions and is thus indispensable as an example of a positive emotion, which can open the doors to the understanding of emotives in the English language and their universal and specific aspects. The paper aims at a better understanding of both universal and specific semantic and cognitive aspects of the given emotion which in linguistics is studied under the term of an emotive. To achieve this purpose the methods of corpus analysis and metaphor analysis have been applied. The study has revealed that positive denotation and almost similar levels of intensity are the universal semantic and cognitive features of the emotive joy.
\end{abstract}

Key words: emotive, joy, cognitive analysis, semantic analysis, universal features.

\section{Introduction}

It is hardly possible to imagine any language devoid of emotives. Indeed, this can be true of any layer of language; however, we believe that without emotives the English literature, newspaper language and many other spheres would be far from being complete. And it is only in rare cases such as academic language that the role of emotives is diminished.

Among the many classifications of emotions, positive and negative emotions can be singled out. Many scholars seem to support this view. Parrot (2001) not only admits them being positive or negative, but he also introduces the notions of primary, secondary and tertiary emotions. 
The wording primary is, we believe, of central importance as in the main manifestations of emotions there is little consensus over which are the basic or primary ones. According to Parrot the class of primary positive emotions encompasses love, joy and surprise, whereas the primary negative class is composed of anger, sadness and fear. Interestingly enough, a vast majority of linguists and emotion scholars highlight joy rather than happiness. This may seem controversial on the surface, but for the sake of this paper, we will view terms joy and happiness as interchangeable as it will allow for a more comprehensive analysis.

\section{Semantic Analysis of Joy}

To start with, we may notice the following definitions of the primary emotive joy:

- a feeling of great pleasure and happiness (Oxford dictionary, 1998);

- the emotion evoked by well-being, success, or good fortune or by the prospect of possessing what one desires (Merriam-Webster dictionary, 2011);

- great happiness and pleasure, or something that gives you this feeling (Longman American English dictionary, 2008).

While the abovementioned definitions may not suffice for a comprehensive analysis of joy, one may note that the common features across the three definitions are pleasure and happiness (as shared by the definitions of Oxford and Longman dictionaries). However, the definition by Merriam-Webster dictionary stands out in this respect as it concentrates more on the reasons behind such an emotive. Besides, Oxford and Longman definitions have included the word feeling which might be a further point of reference for distinguishing between the concepts of emotion (which in linguistics is denoted as an emotive) and feeling.

Here some justification is to be made as to why the word joy was preferred to the word happiness. Coming back to the dispute between whether it is happiness that functions as a primary or basic emotive or this role should be attributed to joy, we may note that the Cambridge dictionary defines the former as "the feeling of being happy" (Cambridge 1995). While the two might look 
like absolute synonyms on the surface, it is common knowledge that the language does not hurry to recognize absolute synonyms (Suárez 1971): joy is hence seen as both a more basic (in some terminology - primary) and a more intensive emotive. As such, it encompasses happiness and pleasure becoming a uniting, binding force for them.

Turning to the definition suggested by Merriam-Webster dictionary, we see that joy is described in terms of the factors that cause such an emotive, i.e. "well-being, success, or good fortune or by the prospect of possessing what one desires". It means that in case of the other 2 definitions, the underlying generality is the experience, feeling of happiness and pleasure, whereas in the latter case joy is seen as a result of actions.

For now, let us turn to another definition, that of Vocabulary.com (Vocabulary.com 2004). This online dictionary is powered by not only standard dictionary definitions but it also boasts classification of types. Its definition runs as follows: "Joy is the emotion of pleasure and happiness. Joy can also be the very thing that delights you." In this sense, it encompasses both the Oxford and Longman understandings of joy as a combination of pleasure and happiness (joy $=$ happiness + pleasure) and the reason behind such an emotive, the process of delighting one.

With regard to the classification of the emotive joy, it differentiates between six types:

1. become cheerful (cheer, cheer up, chirk up);

2. become glad or happy (gladden);

3. feel extreme happiness or elation (be on cloud nine, exult, jump for joy, walk on air);

4. to express great joy (exuberate, exult, jubilate, rejoice, triumph);

5. become more cheerful (buoy up, lighten, lighten up);

6. be ecstatic with joy (rejoice, triumph, wallow).

The common features that can be highlighted are that joy is tightly connected with the process of becoming happy, thus being presented by the action verb become, e.g. become cheerful; become glad or happy; and it even shows a comparative level as in become more cheerful. Out of these six types 
two are described by state verbs feel and be, and the last type includes another action verb, express. Thus, joy in English is either a state or process of becoming glad, happy, cheerful, and so on. Besides, it is the expression of such a state.

Interestingly, even though we have already discussed that in terms of intensity, joy is more than mere happiness or pleasure, the abovementioned classification does not allow much room for a very strict classification of levels of this emotion. It can be generally agreed that Type Three (feel extreme happiness or elation) is the most intense experience of this emotion as it is modified by the adjective extreme. Not surprisingly, it is here that we find idiomatic and metaphoric expressions, such as be on cloud nine, jump for joy and walk on air. Type Six (be ecstatic with joy) might follow suit being almost as strong as Type Three. And Type Four (to express great joy) will come after. Type Five (become more cheerful) will be the next as it shows a comparative level. Thus, in terms of the decrease of intensity of the emotive we will have the following picture:

a. feel extreme happiness or elation (be on cloud nine, exult, jump for joy, walk on air);

b. be ecstatic with joy (rejoice, triumph, wallow).

c. to express great joy (exuberate, exult, jubilate, rejoice, triumph);

d. become more cheerful (buoy up, lighten, lighten up);

However, the classification of intensity is not that straightforward. In the first place, many words denoting joy fall into different categories of intensity, such as exult which is both in the group where the emotive is the strongest and in the third group. This paradox makes the classification somewhat flawed. On the other hand, there is no criterion to distinguish between the levels of intensity of Type One (become cheerful) and Type Two (become glad or happy). To be able to compare these two, we need to have objective tools for comparison which seem to be absent. What can be concluded about level of intensity which is typical to all emotives is that in case of joy this cannot boast a straightforward classification; in other words, all of these types have this or that level of strength of emotive; however, they are not subject to 
comparison, and this is, thus, not a semantic universal for this primary (basic) positive emotive.

To better understand this emotive, we will turn to another classification made recently by the efforts of emotion specialist Dr. Paul Eckman and supported by Dalai Lama (Atlas of Emotions, 2015). They present another online tool, the Atlas of Emotions which encompasses the following basic emotions: disgust, anger, fear, sadness and enjoyment. It is worth noting that enjoyment (which we take to be Atlas' wording for the emotive of joy) is the only positive emotive in the list. The Atlas of emotions has a different term for this emotive: enjoyment. It has twelve semes here which are presented in terms of increasing force. To compare, this is more than the respective semes of the emotive anger by five.

Here is how it is presented:
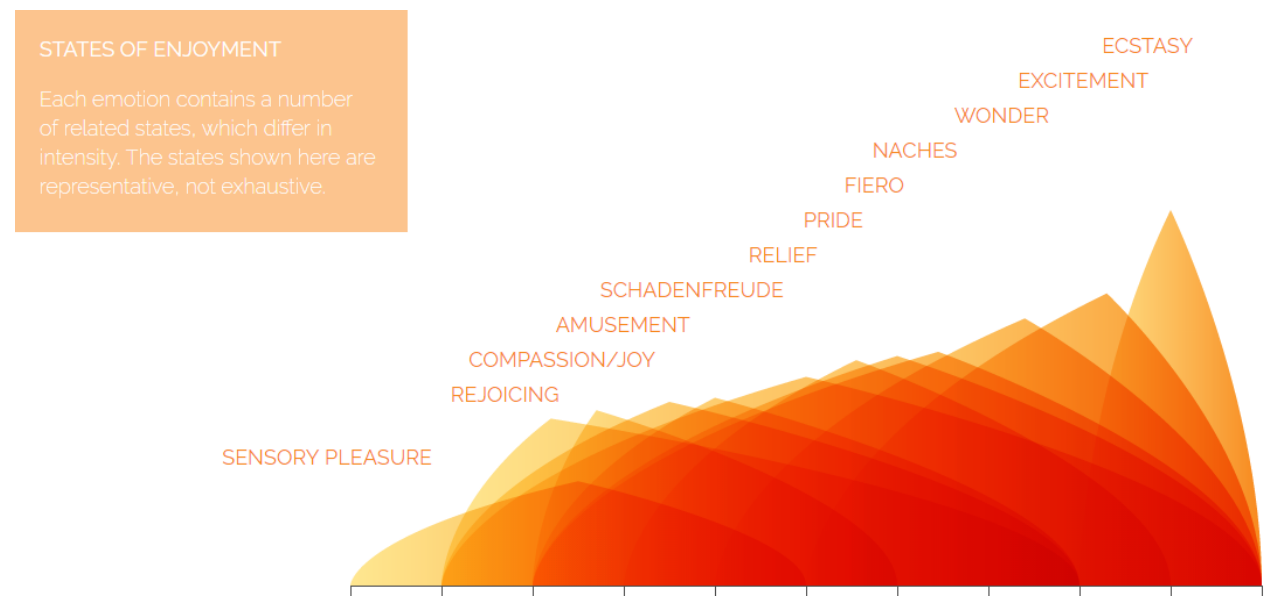

Pic. 1: Joy depicted in the Atlas of Emotions

The explanations behind each of these are also given in the Atlas of Emotions:

1. Sensory pleasure: enjoyment derived through one of the five physical senses: sight, sound, touch, taste and smell. 
2. Rejoicing: A warm, uplifting feeling that people experience when they see acts of human goodness, kindness and compassion. Also called elevation.

3. Compassion/joy: Enjoyment of helping to relieve another person's suffering.

4. Amusement: Light, playful feelings of enjoyment and good humor

5. Schadenfreude: Enjoyment of the misfortunes of another person, usually a rival.

6. Peace: When something expected to be unpleasant, especially the threat of harm, is avoided or comes to an end.

7. Pride: An experience of ease and contentment.

8. Deep pleasure and satisfaction derived from one's own achievements or the achievements of an associate.

9. Fiero: Enjoyment of meeting a difficult challenge (an Italian word).

10. Naches: Joyful pride in the accomplishments of one's children or mentees (a Yiddish word).

11. Wonder: An experience of something that is very surprising, beautiful, amazing or hard to believe.

12. Excitement: A powerful enthusiasm.

13. Ecstasy: Rapturous delight. A state of very great happiness, nearly overwhelming.

The Atlas of Emotions seems to solve the problem of classifying this emotive starting from the least intense (sensory pleasure) to the most intense one (ecstasy). Joy, interestingly, goes hand in hand with compassion and is the third least intense emotive on the chart. It should, however, be mentioned that as opposed to dictionary definitions and classification of types provided by Vocabulary.com, this is a work compiled by non-linguists. That is to say, that even though a classification of the levels of intensity of the emotive joy does exist, first of all there is no consensus over it and, secondly, it may not be regarded as an established universal. What is a universal feature though is that emotives, in this case, emotives showing joy do vary in degrees of intensity, but in the words of the Atlas, their representation is "representative not exhaustive" (Altas of Emotions, 2015).

Not only does the Atlas seem to depict the intensity of each emotive, but it also turns to the duration of each. In this respect we will have the following 
classification: ecstasy, compassion/joy, sensory pleasure, excitement, schadenfreude, pride, wonder, rejoicing, amusement, fiero, naches, relief. If the special distribution of two among these was the same, we prioritized the ranking of emotives based on increase in intensity.

The degrees of intensity thus are not fully agreed upon, and we should look for other universal semantic features. One of them is the state of being positive, as mentioned above. The seemingly positive emotive joy, though, is not that black and white: it may have shades of negative meaning, as its secondary and tertiary emotions (again, according to Parrot), may encompass pride which itself can be sometimes regarded as a negative emotive, as in "If the blockade was lifted, there is so much pro-Qatar sentiment and nationalist pride that the people will buy Qatar milk, not Saudi." (The Guardian, October 20, 2017). The word expression nationalist pride (as opposed to, for example, national pride) shows a negative connotation.

\section{Visual thesaurus; metaphor analysis}

To further illustrate this concept, we would like to turn to Visual thesaurus which is an online tool for corpus analysis (the Visual Thesaurus, 2004).

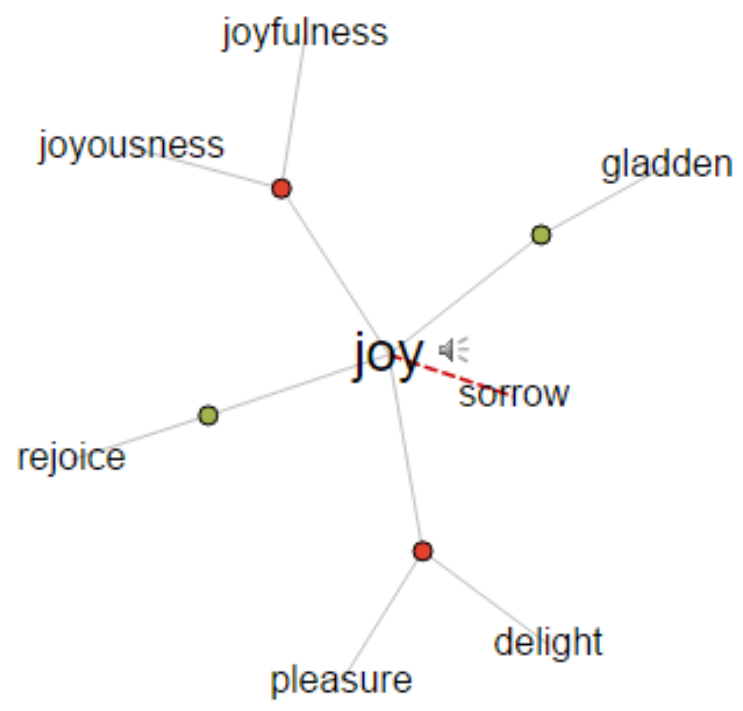

Pic. 2: Joy depicted in the Visual Thesaurus 
The visual representation shows that this emotive is almost equally distanced from the following definitions (mentioned clockwise): the emotion of great happiness (joyousness, joyfulness), making glad or happy (gladden), something or someone that provides a source of happiness (delight, pleasure), feeling happiness or joy (rejoice). This emotive is thus perceived as an emotion, a process, a state or an actor that causes this emotion. There is very little controversy over the universal semantic features in this respect which are as follows:

1. The emotive is always positive.

2. It has clear-cut levels of intensity.

3. It has a positive denotation.

That is to say, in terms of universal linguistic features it is a most stable emotive as its many dictionary definitions and depictions allow concluding. However, language is a complex body of meanings which are not often clearcut. To illustrate this, we would like to turn to metaphors denoting joy. Kövecses (1991b:24-25) and Lakoff \& Johnson (1980) note the following metaphors for joy:

1. Happy is up: We had to cheer him up.

2. Happiness is being off the ground: I am six feet off the ground. I was so happy my feet barely touched the ground.

3. Happiness is being in heaven: That was heaven on earth.

4. Happy is light: She brightened up at the news.

5. Happy is vitality: She was alive with joy.

6. Happy is warm: That warmed my spirits.

7. A happy person is an animal that lives well: He was happy as a pig in shit. He looks like the cat that got the cream.

8. Happiness is a pleasurable physical sensation: I was tickled pink.

9. Happiness is a fluid in container: He was overflowing with joy.

10. Happiness is a captive animal: His feelings of happiness broke lose. She couldn't hold back her feelings of happiness.

11. Happiness is an opponent in a struggle: He was knocked out! She was overcome by joy! 
12. Happiness is a rupture/high: I was drunk with joy.

13. Happiness is insanity: They were crazy with happiness.

14. Happiness is a natural force: He was swept off his feet.

The previously seemingly clear-cut emotive is not manifested in a far more complex way. In the first place, the emotion is seen as a state: just as in the preceding classification from the visual thesaurus, here we have joy as a state (being off the ground, being in heaven, a fluid in container, etc.). However, it is also a process as in to be drunk with joy, to be swept off one's feet and in other examples. Joy is a vertical emotion with an upward vector, e.g. I was so happy my feet barely touched the ground or heaven on earth. Joy indicates a place, heaven. This is an emotive that is well associated with animals ( $\mathrm{He}$ looks like the cat that got the cream and others). Thus, rearranging the metaphors we will get the following picture: the universal features of joy are showing a state or action, being associated with upward movements and some others. On hindsight, though, not every emotion is supposed to have a direction so that it is not a universal feature for all emotives in the English language, it seems.

\section{Conclusion}

Among the many emotives of the English language joy is characterized by a number of features: it has a positive denotation but may have a negative connotation as it is associated with the feelings of pride. It is both a state and an action. It boasts levels of intensity which are relatively clear-cut. In addition, this emotive makes part of a variety of metaphors which emphasize its strong positive side. However, the emotive is also distinguished from others in that it is metaphorically associated with animals; it has an upward vector and it may be a place. This makes for the specific semantic and cognitive features of this emotive. 


\section{References:}

1. (2015) Atlas of Emotions. Available at: <http://atlasofemotions.org> [Accessed November 2017].

2. (1995) Cambridge English Dictionary. Available at: <https://dictionary. cambridge.org/dictionary> [Accessed November 2017].

3. Kövecses Z. (2003) Metaphor and Emotion: Language, Culture, and Body in Human Feeling. // Language Arts \& Disciplines. Cambridge: CUP.

4. (2008) Longman Dictionary of American English. Pearson.

5. (2011) Merriam-Webster.com. Available at: <https://www.merriam-webster. com> [Accessed November 2017].

6. (1998) Oxford Advanced Learner's Dictionary of Current English. Oxford.

7. Parrott, W. (2001) Emotions in Social Psychology: Essential Readings.. University of Maryland: Psychology Press.

8. Suárez, J.A. (1971) A Case of Absolute Synonyms. // International Journal of American Linguistics 37, N. 3, pp. 192-195.

9. (October 20, 2017) The Guardian. Available at: <ttps://www.theguardian. com/world/2017/oct/20/land-of-milk-and-money-qatar-looks-to-farms-tobeat-the-gulf-boycott $>$ [Accessed November 2017].

10. (2004) The Visual Thesaurus. Available at: <https://www.visualthesaurus. com> [Accessed November 2017].

11. (2004) Vocabulary.com. Available at: <https://www.vocabulary.com/ dictionary> [Accessed November 2017].

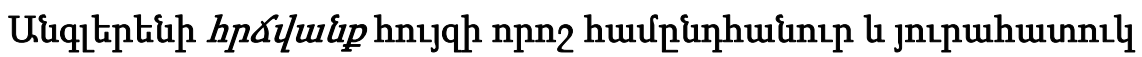

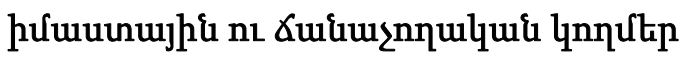

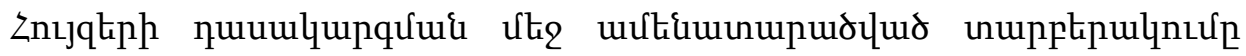

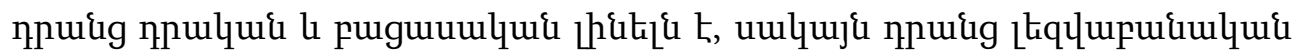

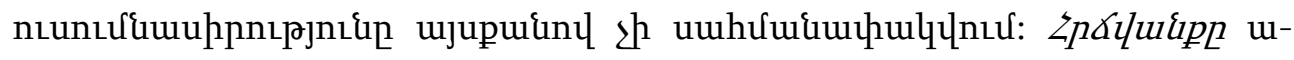

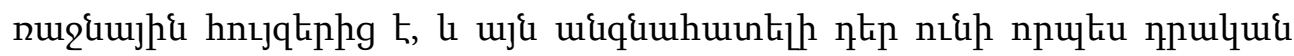




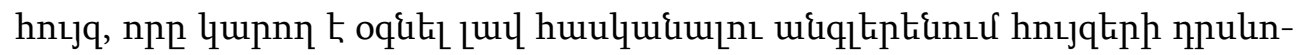

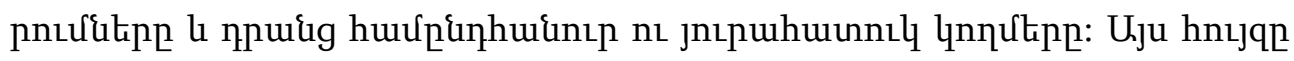

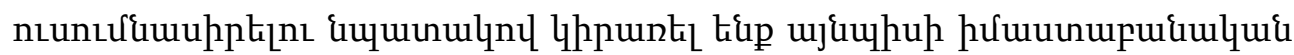

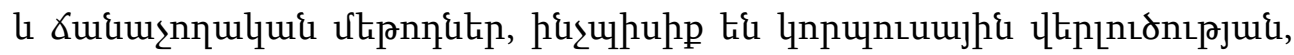

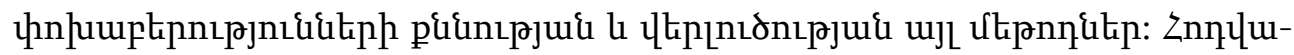

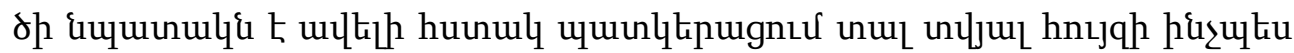

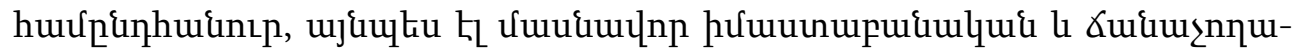

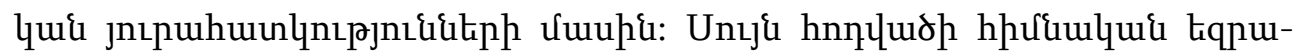

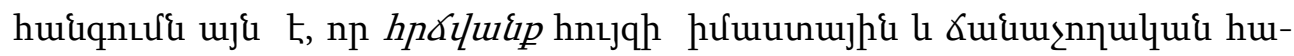

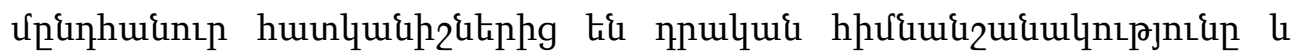

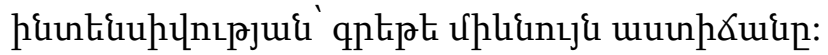

